\title{
Elos entre ecofeminismo, agroecologia e soberania alimentar
}

\author{
adriella Camila Gabriela Fedyna da Silveira Furtado da Silva \\ Rubia Carla Formighieri GIORDANI \\ ISLANDIA BEZERRA
}

\begin{abstract}
RESUMO: $\quad$ Esta pesquisa problematiza as concepções de gênero e natureza, interligando o(s) ecofeminismo(s) à agroecologia e à soberania alimentar. Sistemas agroalimentares protagonizados por mulheres dão concretude a um projeto social direcionado para a soberania alimentar e estimulam novas relações entre seres humanos e natureza, modos de vida e consumo, que passam a ser pensados de forma integrada.
\end{abstract}

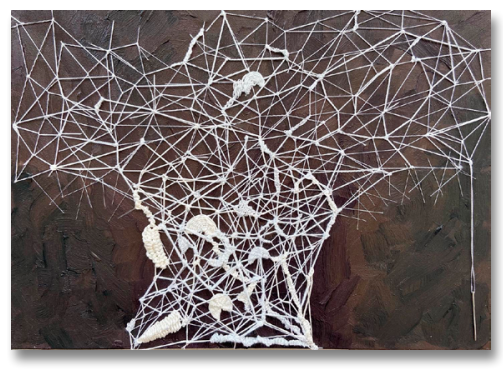

Palavras-chave: Ecofeminismo. Gênero. Agricultura Sustentável. Soberania Alimentar.

\section{Links between ecofeminism, agroecology and food sovereignty}

adriella Camila Gabriela Fedyna da Silveira FurTado da SILVA

Mestre em Alimentação e Nutrição pela UFPR.

E-mail: adriellacamilagabrielafurtado@ gmail.com

\section{Rubia Carla Formighieri GIORDANI}

Professora na área de Saúde Pública do Departamento de Nutrição e colaboradora no Programa de PósGraduação em Sociologia na UFPR. E-mail: rubiagiordani@gmail.com

\section{ISLANDIA BEZERRA}

ABSTRACT: This research problematizes the conceptions of gender and nature, linking ecofeminism(s) to agroecology and food sovereignty. Agri-food systems led by women give concreteness to a social project aimed at food sovereignty and stimulate new relationships between human beings and nature, lifestyles, and consumption, which come to be thought of in an integrated way.

Keywords: Ecofeminism. Gender. Sustainable Agriculture. Food Sovereignty.

RECEBIDO: 24/03/2020

Professora vinculada ao

Departamento de Nutrição e ao

Programa de Pós-Graduação em

APROVADO: 05/01/2021

Sociologia/PGSOCIO da UFPR.

E-mail: islandiabc@gmail.com 


\section{Introdução}

Este artigo aborda as conexões entre as temáticas do ecofeminismo, da agroecologia e da Soberania Alimentar (Sobal). A indagação norteadora que instigou a reflexão foi: quais são as concepções atribuídas às categorias gênero e natureza que interligam o ecofeminismo e a agroecologia, e como elas se concatenam com a Soberania Alimentar?

Trata-se de pesquisa bibliográfica, documental, exploratória, descritiva e de cunho ensaístico, que surgiu a partir da identificação de lacunas com abordagem interdisciplinar. Dessa forma, definiu-se como objetivo contextualizar e compreender os pressupostos que embasam estas temáticas, buscando possibilidades de aderência e suas interconexões. O presente ensaio parte de um movimento dialético que articula conceitos para compreender a realidade, fazendo-os colidir na medida em que inicialmente teriam apenas relação remota.

Inicia-se o debate historicizando o conceito de ecofeminismo, destacando o processo pelo qual esta linha de pensamento se legitimou social e intelectualmente. Na sequência, expõe-se uma reflexão a respeito do alimento, das atividades de cuidado e das relações estabelecidas entre as mulheres e a natureza nas perspectivas agroecológica e ecofeminista. E na última seção, são apresentados e discutidos os elos entre agroecologia, Sobal e ecofeminismos.

\section{Método}

A fundamentação teórica e filosófica do presente artigo apoiou-se na seleção de fontes de interesse dos repositórios EBSCO Information Services, SciELO (Scientific Eletronic Library Online) e Portal de Periódicos Capes, considerando-se as seguintes etapas de leitura para a verificação da elegibilidade: títulos, resumos e artigos na íntegra.

Com o intuito de alcançar o objetivo proposto, foram eleitos os seguintes descritores indexados ao DeCS - Descritores em Ciências da Saúde: "Ecofeminism" (Ecofeminismo), "Agroecology" (Agroecologia) e "Food Sovereignty" (Soberania Alimentar). No emprego dos operadores booleanos, foi utilizada a estratégia de 
busca: ("Ecofeminism”) AND ("Agroecology"); ("Ecofeminism”) AND ("Food Sovereignty"); ("Agroecology") AND ("Food Sovereignty"); ("Ecofeminism") AND ("Food Sovereignty") AND ("Agroecology"). Também foram critérios de inclusão: estudos publicados entre os anos de 2014 e 2019 (considerando-se um período mais recente da produção científica); texto completo; revistas acadêmicas; periódicos científicos; e artigos revisados por pares, nos idiomas inglês, português e espanhol, vinculados aos assuntos referentes a ecologia agrícola, sustentabilidade, mulheres e meio ambiente, não havendo restrição quanto ao desenho de estudo. Excluíramse estudos repetidos, publicações que não se encontravam disponíveis na íntegra, comentários, editoriais, resenhas, críticas, relatórios científicos e estudos que não contemplavam abordagem ecofeminista e em que houvesse a ausência de articulação entre as três temáticas intencionadas.

Na EBSCO, para a pesquisa do descritor Ecofeminism, obtiveram-se 53 materiais. Na SciELO, foram encontrados 17 resultados, e, no acervo do Portal de Periódicos Capes, houve um total de 143 achados. Após a leitura dos resumos desses 213 materiais, foram selecionados 23 artigos de interesse para leitura na íntegra, relacionados às concepções ecofeministas.

Ainda com relação à EBSCO, utilizando os booleanos Ecofeminism and Agroecology, foi encontrado apenas um material, sem abordagem relacionada ao ecofeminismo e sem adequação ao delineamento deste estudo. Ademais, apenas um material de interesse foi encontrado na busca Ecofemism and Food sovereignty. Já nas bases SciElO e Periódicos Capes, para ambos os termos associados, não foram identificados resultados.

Em seguida, quando correlacionado Agroecology and Food Sovereignty, foram obtidos 45 achados na EBSCO, dos quais 10 materiais eram de interesse, pois apresentavam articulação das temáticas. Para essa combinação, na SciELO foram encontrados 13 materiais, dos quais dois eram de interesse deste trabalho. Já no Periódicos Capes, a pesquisa correspondeu a 62 achados, dos quais três eram de interesse. Por fim, nos três repositórios, quando agregados Ecofeminism and Agroecology and Food Sovereignty, não foram retornados resultados. 
Ao final das aplicações dos critérios de busca, foram encontrados para análise 39 materiais de interesse, na íntegra: 17 fontes na EBSCO, sete artigos na Scielo e 15 materiais no Portal Periódicos Capes. Para complementar a discussão, compuseram este ensaio outras referências extras, tais como livros, anais, revistas, coletâneas, relatórios e trabalhos acadêmicos, das áreas de conhecimento relacionadas a agroecologia, gênero e ecofeminismo.

\section{Ecofeminismo(s): histórico da construção do conceito}

O pensamento ecofeminista foi engendrado em 1970, a partir dos movimentos feministas, durante a segunda onda do feminismo. Nesse período, suas origens teóricas tiveram como precursora a escritora Françoise D'Eaubonne, que cunhou o termo ecofeminismo, em sua obra "Le féminisme ou la mort" ("Feminismo ou morte'). A autora evidenciava o controle patriarcal sobre a sexualidade feminina e refletia sobre a opressão às mulheres e à natureza, salientando a necessidade de desenvolver uma nova estrutura nas relações de gênero e entre a humanidade e o meio ambiente, como apontado por Connell e Pearse (2015).

Embora existissem várias maneiras de pensar a relação entre gênero e natureza nesse período, Rebecca Evans (2015) ressalta que James Tiptree Jr., escritor de ficção científica, oferecia uma exploração de como as preocupações ambientais e feministas já se manifestavam de forma entrelaçada, fornecendo uma nova entrada textual dentro do ecofeminismo, o que permitiu observar como várias abordagens ecofeministas e atitudes essencialistas estavam enredadas.

Em virtude dessa conjuntura, o Ecofeminismo passou a ser reconhecido como uma corrente de atuação prática e teórica, cujas demandas trariam, para o cerne do debate, reivindicações de uma agenda social e política em defesa de direitos na perspectiva analítica de gênero. Ao mesmo tempo, também sinalizaria as problemáticas ambientais como consequências do patriarcado, do qual o antropocentrismo e o androcentrismo estariam alinhados e convergentes (PULEO, 2008). 
Nessa seara de debate, complementa-se a discussão com apontamentos que, de um lado, afirmam que a visão antropocêntrica (e toda sua produtividade na cultura capitalista) subtrai a potência e a energia da vida dos outros seres ao desenhar racionalidades que organizam (com transações desiguais) o mundo social e produzem o açambarcando do mundo natural (GIORDANI; BEZERRA; ANJOS, 2017); de outro lado, alega-se que a visão androcêntrica, centrada no masculino, ratifica a realidade de homens e mulheres à sombra dos modelos masculinos de observação e atuação no mundo (RAMÍREZ; MÁRQUEZ, 2010).

A desconstrução dos dualismos de valor, que se configuram como um sistema de dominação - que incluem gênero, raça, classe social, dominação da natureza e do Outro, todos ligados em um nível conceitual e material, dentro de relações hierárquicas (mulher/homem, seres humanos/natureza, razão/emoção, privado/público, corpo/mente) - se tornou estrutural no pensamento Ecofeminista (SESMA, 2016).

De acordo com Lizbeth Sagols (2014), analisando Karen Warren (2003), existem estruturas conceituais (e reais) opressoras, socialmente construídas, entendidas como o conjunto de crenças básicas, cujos valores e atitudes dão forma e refletem como alguém vê a si mesmo e ao mundo, e que, por sua vez, perpetuam a lógica da dominação como algo imutável e as utilizam como argumento para justificar os diferentes níveis de opressão.

Algumas autoras ecofeministas, como Verónica Blanco (2014), corroboram as concepções anteriores ao acentuarem a necessidade de uma revisão da relação entre a humanidade e a biosfera, e do modelo mecanicista e cartesiano que subordina qualquer forma de existência à dos humanos. Como alternativa, propõe-se o resgate do Ser, ajustado à diversidade, a partir de um convívio sem dominante e dominado, visando sempre à complementação (ROSENDO, 2015).

Nessa perspectiva, Triana (2016) sustenta que a teoria ecofeminista tem potencial inestimável para promover um modelo de conhecimento científico mais empático, pois se compromete com a criação de novas formas de interpretar eticamente o mundo, superando as dicotomias conceituais e reforçando a visão do coletivo, da integridade das vidas e da interdependência. 
Ações no mundo todo, protagonizadas em geral por mulheres e relacionadas a atos de resistência, enfrentamentos e greves contra o sistema global, indicam que o ecofeminismo está em ascensão. Uma dessas ações ocorreu em 2017, no Dia Internacional da Mulher, quando, em mais de 50 países, as mulheres anunciaram uma greve contra o trabalho doméstico e a produção de força de trabalho, provocando o reconhecimento de que os lucros vêm indispensavelmente da natureza e do trabalho das mulheres (GIACOMINI; TURNER; ISLA; BROWNHILL, 2018). Nesse contexto, a ação ecofeminista afirma a defesa dos bens comuns e das relações socialmente mais justas para o controle compartilhado sobre os meios de vida.

Josefina Vivar-Arenas (2015) e Diana Triana (2016) ressaltam que não há um único corpus ético ou uma só postura ecofeminista, visto a sua heterogeneidade em termos de discussões, categorias e intenções éticas; e, uma vez que o ecofeminismo não é um só, mas múltiplo, torna-se mais apropriado falar em Ecofeminismos. No presente ensaio, dá-se foco à tendência construtivista, mas sublinhando a força e potência de mobilização de todas as tendências ecofeministas.

A vertente construtivista não analisa a relação entre mulher e natureza por meio de características supostamente intrínsecas e dadas, mas sim pela responsabilidade que as mulheres adquiriram historicamente na garantia da sua sobrevivência, na interação com o ambiente e na reprodução da sociedade, bem como contribui para mobilização de discussões acerca dos processos sexuados, trazendo referenciais sociais, históricos e empíricos para demonstrar como um mundo binário produz diferentes subjetividades (MUDREK, 2015).

Junto a esse cenário de discussões no campo das ideias, ocorrem enfrentamentos reais e cotidianos, como destacado por Severino Silva (2017) ao expor que, dentre as lutas em defesa da natureza que os movimentos ecofeministas brasileiros enfrentam, estão principalmente a resistência às barragens e à privatização da água, ao uso de agrotóxicos e de sementes transgênicas, e às usinas nucleares. Esses movimentos expressam ainda um protagonismo na construção de alternativas populares e sustentáveis, como veremos a seguir, mediante a proposta agroecológica. 


\section{Mulheres, natureza e cuidado}

De acordo com Giordani, Bezerra e Anjos (2017), a agroecologia pode despertar a sociedade para novas relações com a natureza. A produção do alimento agroecológico aciona diferentes redes de sentido, e a este faz-se referência como comida de verdade. Comida essa que alimenta corpo, mente e espírito.

A agroecologia se alinha à perspectiva ecofeminista à medida que, no cotidiano das mulheres, suas práticas de produção e de consumo de alimentos agroecológicos lhes permitem olhares ressignificados para e com a natureza e com os outros seres. Esses novos olhares incidem em novas posturas de enfrentamento e de resistência ao sistema global, o qual está pautado por relações mercantilizadas, pelo alimento mercadoria e pelas relações patriarcais de poder.

Concatenado à perspectiva anterior, Warren (2003) enfatiza que a natureza (árvores, água, animais) e a produção de alimentos podem e devem ser inseridos no contexto do debate feminista, pois abarcam interconexões (mulheres-outros-humanos-natureza) que auxiliam a entender por um lado, a dominação das mulheres e de outros grupos dominados, e, por outro, a dominação da natureza.

As mulheres se mantiveram por longo tempo em desvantagem em relação aos homens por causa de concepções historicamente aceitas, embasadas em ideais que afetam desproporcionalmente mulheres e homens e que foram construídas sobre bases econômicas e religiosas que subjugam a mulher e a natureza ao desejo e à ação masculina (CARMO et al., 2016).

Tais concepções já eram evidenciadas desde o século XVIII por Mary Wollstonecraft (1759-1797), em seu livro "Vidications of the Rights of Woman" ("Reivindicação dos direitos da mulher") (2015), cuja primeira edição foi publicada em 1792, no qual já antecipava modernos conceitos feministas. Em sua obra, a autora constata as causas da subordinação das mulheres a um processo histórico de dominação masculina, passíveis de mudança por meio do exercício da razão - visto que havia, em parte, um processo de imposições sociais que submetiam as mulheres a uma posição em que quase não lhes cabiam outras escolhas. 
Emma Siliprandi (2008), analisando Bina Agarwal e Val Plumwood, constatou que a base da opressão feminina reside nas condições materiais de existência, pela posição que historicamente as mulheres ocuparam e com gênese na racionalidade dominadora masculina. Exprime este processo, a divisão sexual do trabalho, que designa as tarefas de reprodução e de cuidado para as mulheres, e as de produção (monetária) para os homens, com uma história de valorização social desigual.

Marie-Anne Casselot (2015) destaca a abordagem ecofeminista de Sherilyn MacGregor, apontando que a distribuição do trabalho de cuidado é uma questão relacionada à transformação global da economia. Na luta por novas formas ecológicas de repensar cidades e comunidades sustentáveis, evidencia que é preciso considerar a distribuição dos trabalhos fundamentais e indispensáveis para a sustentabilidade da vida, tais como as atividades de cuidado. Com relação a essas atividades, Casselot (2015) afirma que é imperativo ter um debate público sobre quem faz o quê, quando, como e sob quais condições.

Lori Swanson (2015) reafirma que as responsabilidades de cuidado devem ser compartilhadas entre toda humanidade, endossando a adoção de uma visão combinada da ética ecofeminista do cuidado. Nessa lógica, Vivar-Arenas (2015) sinaliza que o ecofeminismo assume um compromisso com as relações cooperativas, igualitárias e ecologicamente sustentáveis entre a humanidade e a natureza, atendendo a uma perspectiva holística e receptiva aos compromissos e às responsabilidades individuais e de grupo.

Para evitar a feminização do trabalho de cuidado, uma abordagem ecofeminista da cidadania tornaria a prática de cuidados uma parte crucial do engajamento político. Se todos e todas participassem das práticas de cuidado, sua carga de gênero diminuiria. Nesse contexto, Casselot (2015) considera que as atividades de cuidado devem ser valorizadas e consideradas como contribuição importante e como trabalho necessário para a sociedade, independente do gênero, reconhecendo a natureza humana interdependente e enfatizando a necessidade dos seres humanos em sintonizar e responder a outros seres e a forças que habitam em um mundo compartilhado. 
No âmbito dos territórios rurais, tanto as mulheres, como a natureza e a agroecologia, vêm ganhando visibilidade a partir de suas lutas e dos enfrentamentos cotidianos - situações que expressam a força, a resistência e a resiliência da mulher, da natureza e da agroecologia. Maria Emilia Pacheco foi a primeira autora brasileira a evidenciar o protagonismo das mulheres na agroecologia, conforme cita Emma Siliprandi (2015). Ao evidenciar as desigualdades em diferentes dimensões da vida das mulheres, Pacheco constata a subestimação e a invisibilidade dos trabalhos desenvolvidos pelas mulheres, quando se parte da premissa de complementaridade do trabalho feminino à atividade exercida pelo homem.

De outro lado, notam-se esforços agroecológicos e ecofeministas, sejam teóricos, propositivos ou práticos, para dar voz e visibilidade às experiências que permeiam a produção e o consumo de alimentos e à relação mulher-natureza-alimento, pautadas em ser-fazer ressignificadas, harmoniosas, conscientes e coletivas. Nesse processo, para fortalecer a agroecologia, a luta pela sustentabilidade e pelos direitos das mulheres e da natureza, é preciso concretizar uma efetiva revisão e uma mudança nas relações de gênero e da humanidade com a natureza e outros seres, baseada em igualdade, equidade, solidariedade, compartilhamento de tarefas de cuidado e valorização da vida.

\section{Agroecologia, soberania alimentar e ecofeminismo(s)}

Desde que o termo agroecologia foi usado pela primeira vez em 1928, seu significado enquanto campo de conhecimento, como ciência, prática e movimento social, evoluiu e se expandiu, abrangendo todo o sistema alimentar, desde a utilização do solo até o debate sobre direitos humanos (WEZEL et al., 2018).

Enquanto ciência, a agroecologia fornece bases conceituais e metodológicas para o desenvolvimento de agroecossistemas sustentáveis, priorizando abordagens holísticas, participativas e transdisciplinares. Como prática, baseia-se no uso sustentável de recursos renováveis, nos conhecimentos de agricultores e agricultoras locais e na manutenção de agroecossistemas 
biodiversificados. Na qualidade de movimento social, defende a soberania e a segurança alimentar e nutricional, a equidade de gênero, relações mais equilibradas entre o rural e o urbano, sistemas curtos de comercialização, economia solidária, diversidade de sementes e de raças nativas, justiça social e alimentos saudáveis (WEZEL et al., 2018).

Segundo Iracema Moura, Cezar Guedes e Renato Assis (2017), desde 2003, no Brasil, a perspectiva agroecológica está presente em políticas públicas pontuais. No entanto, essa perspectiva apenas passou a ser incluída na agenda de decisão de políticas públicas a partir do alerta para a Presidência da República do Brasil, em 2011, sobre a necessidade e urgência de uma Política Nacional de Agroecologia, feito pela Marcha das Margaridas, cuja composição engloba mulheres, movimentos feministas, associações e sindicatos.

Nesse panorama, em 2012, a ação convergente do movimento agroecológico e da produção orgânica, com contribuições de organizações de mulheres, combinadas com o momento político favorável, foram fundamentais para criação de espaços para inclusão da agroecologia na agenda governamental e na formulação da Política Nacional de Agroecologia e Produção Orgânica (Pnapo) e do Plano de Agroecologia e Produção Orgânica (Planapo). Apesar de suas limitações, a Pnapo e o Planapo podem ser considerados marcos, tendo assegurado a agenda agroecológica nas políticas públicas relacionadas ao desenvolvimento rural, à Soberania Alimentar e ao Direito Humano à Alimentação Adequada (DHAA) (MOURA; GUEDES; ASSIS, 2017).

Abril Tejeda (2015) atribui relevância à participação social das mulheres em programas de desenvolvimento ambiental sustentável, por se tratar de uma questão de cidadania que dá voz, aumenta a capacidade de autogestão e de participação local e comunitária.

Dentre as iniciativas dos movimentos sociais direcionados à estruturação de espaços para inclusão da agroecologia na agenda governamental, grupos obtiveram apoio de um número crescente de acadêmicos, cientistas, ONGs, alguns programas do governo, especialmente em relatórios apresentados ao Conselho de Direitos Humanos das Nações Unidas (2008-2014), escritos por Olivier 
de Schutter, relator especial das Nações Unidas para o Direito à Alimentação (LACEY, 2015).

Colin Sage (2014) sinaliza ativistas defensores da Sobal, destacando Schutter, que tem sido um firme proponente da agroecologia como ferramenta para a mudança do sistema alimentar, promotora de justiça social, acesso, resiliência, resistência e sustentabilidade. Já Anne Deepak (2014) frisa uma das declarações do relator, o qual afirmou que pesquisas sobre o rendimento das culturas em projetos agroecológicos mostraram um aumento médio de 80\% em 57 países em desenvolvimento, e um aumento médio de 116\% para todos os projetos africanos.

No Brasil, existem muitas experiências em agroecologia que estão ganhando expressão política, uma vez que tem legitimado seu potencial na promoção de uma agricultura sensível à nutrição humana adequada. Experimentos que articulam práticas agroecológicas e estratégias de soberania e de segurança alimentar e nutricional envolvem diversas dimensões, como o resgate e conservação da agrobiodiversidade, a diversificação de sistemas produtivos, a recuperação de alimentos regionais e a visibilidade do protagonismo das mulheres (MALUF et al., 2015).

Destaca-se que muitas dessas (e de outras) experiências em agroecologia estão diretamente conectadas às questões ecofeministas, como podem ser notadas pelas articulações das estratégias descritas anteriormente e de outras tantas que cotidianamente são desenvolvidas pelas mulheres.

Em diversos setores, desde projetos de agroecologia e sustentabilidade urbana até iniciativas de energia renovável e campanhas de desinvestimento em combustíveis fósseis, as mulheres estão na linha de frente dos esforços globais para defender a natureza e os seus direitos, trabalhando como líderes indispensáveis, em muitas respostas efetivas, contra o atual curso evolutivo da humanidade.

No entanto, suas vozes frequentemente não são ouvidas, apesar de falarem e agirem com força e liderança. Isso não é surpreendente, considerando-se a discriminação de gênero e as violações sistemáticas dos direitos das mulheres. Esses abusos reforçam a ligação inseparável entre a violência contra as mulheres e a exploração da natureza e dos seres pelo capitalismo (LAKE, 2018). 
Na mesma direção, Irving e Helin (2018), a partir de uma leitura ecofeminista do discurso de desenvolvimento sustentável, destacam que, muitas vezes, esse discurso se pauta em uma visão instrumental da natureza. Frequentemente, o extrativismo de combustíveis fósseis e o agronegócio prejudicam e ameaçam a base da vida e do sustento das mulheres, visto que as separam de seus meios de vida - territórios, sementes, água - mercantilizando e degradando a natureza, minando as relações sociais e os bens comuns.

McKinney (2014) destaca que a degradação ecológica afeta diretamente as mulheres e restringe a democracia. Inversamente, o potencial de igualdade política e de gênero pode impulsionar a sustentabilidade ecológica.

Nesse processo, Osprey Lake (2018) acentua que, quando as mulheres ganham espaço para aumentar seu poder e atuação, há benefícios para comunidades e sociedades, apontando como exemplos a expansão de economias sustentáveis, os ecossistemas locais prósperos, assim como as experiências no Sul global, nas quais as mulheres são responsáveis por parte significativa (40-80\%) da produção doméstica de alimentos.

Noelia Melero-Aguilar e Dolores Limón-Domínguez (2017) destacam que, sob uma perspectiva ecofeminista, a educação para a sustentabilidade fornece as chaves para outro desenvolvimento, a partir do qual se promove a harmonia com a natureza, mudanças pessoais e estruturais para garantir a conscientização dos cidadãos e cidadãs sobre os problemas ambientais e a distribuição equitativa dos recursos entre os seres humanos.

Os papéis de gênero e a dependência de recursos para subsistência são particularmente importantes na formação de conhecimento e de preferências para sua preservação. Assim, há processos em que as mulheres assumem importantes posições no gerenciamento do manejo e da conservação da biodiversidade, como é o caso da agroecologia (MEINZEN-DICK; KOVARIK; QUISUMBING, 2014).

Nesse contexto, diversas experiências protagonizadas por mulheres vêm sendo evidenciadas, como na pesquisa de Leigh Brownhill, Wahu Kaara e Terisa Turner (2015), na qual explicitam uma iniciativa agrícola agroecológica em que alianças de gênero e geracional, enraizadas em tornar o acesso à terra mais equitativo, são a chave para o poder de transformação. 
Pesquisas como a de Siliprandi (2015), e ainda outras tantas sistematizações e coletâneas, têm agregado experiências agroecológicas protagonizadas por mulheres no meio rural e urbano, em diferentes regiões brasileiras e no exterior, fornecendo bases e ferramentas para a mudança do sistema alimentar hegemônico e oferecendo a oportunidade de autonomia e de autossuficiência alimentar.

Contudo, ainda existe a necessidade de se reiterar a importância de priorizar a igualdade de gênero para a justiça social e o reconhecimento da liderança e dos conhecimentos das mulheres na agroecologia. Dessa forma, é possível compreender que, ainda que permeiem enfrentamentos e lutas, as contribuições das práticas produtivas cotidianas de diversas mulheres têm favorecido de forma decisiva, na prática e na teoria, a construção da Soberania Alimentar.

De acordo com Anne Portman (2018), a Soberania Alimentar afirma o direito dos povos de definir e organizar seus próprios sistemas agrícolas e alimentares, a fim de atender às necessidades locais e assegurar o acesso a terra, água e sementes, sendo um conceito baseado na dispersão de poder (de forma igualitária) e que valoriza a tomada de decisão democrática.

Em 2001, no Fórum Mundial sobre Soberania Alimentar, realizado em Cuba, a rede internacional de movimentos sociais, denominada La Via Campesina (LVC), estabeleceu a Soberania Alimentar como: o direito de cada povo a definir suas próprias políticas agropecuárias e alimentares, a proteger e regulamentar a produção agropecuária nacional e mercados domésticos, a fim de alcançar o desenvolvimento sustentável, e que defende a opção de formular políticas e práticas comerciais que melhor sirvam aos direitos da população, a dispor de métodos e alimentos inócuos, nutritivos e ecologicamente sustentáveis (LVC, 2001).

Indo além, segundo Colin Anderson, Chris Maughan e Michel Pimbert (2018), a Soberania Alimentar foi assumida por movimentos sociais urbanos e rurais como um projeto político de transformação do sistema alimentar, que enfatiza a democratização da agricultura e da alimentação, os direitos e a autonomia de produtoras e produtores. 
A Via Campesina é uma rede transnacional de 150 organizações locais e nacionais em 70 países da África, Ásia, Europa e Américas, que inclui camponeses e camponesas, agricultores e agricultoras familiares, sem-terra, indígenas, migrantes e trabalhadores e trabalhadoras agrícolas (DEEPAK, 2014). Fundada desde 1993, defende a agroecologia como resposta para transformar o sistema alimentar hegemônico (WEZEL et al., 2018). Ademais, a Via Campesina compartilha a visão de que a agroecologia é uma ferramenta coletiva de transformação de realidades, sendo um alicerce para a construção da Soberania Alimentar (ANDERSON; MAUGHAN; PIMBERT, 2018).

Essas aspirações da Via Campesina moldam suas políticas e lutas, que, por sua vez, reivindicam a Sobal como um direito, necessária para concretizar e salvaguardar a garantia à segurança alimentar e para incorporar atitudes éticas em relação à natureza (respeitar, restaurar, sustentar, cultivar, contemplar, apreciar, desfrutar, harmonizar, aprimorar), que preservem a biodiversidade e assegurem os poderes regenerativos da natureza. Da mesma forma, a Via Campesina afirma que este processo deve ser conectado com a agroecologia, mediante relações sociais livres de opressão e desigualdade (LACEY, 2015), pautadas em relações horizontais de cooperação e na defesa coletiva dos bens comuns.

Nesse sentido, ao analisar como a agroecologia pode ser fortalecida de maneira estratégica pelos movimentos sociais para promover a Sobal, Anderson, Maughan e Pimbert (2018) estabelecem quatro processos-chaves: abordagens horizontais de aprendizado; diálogo de saberes; combinação de conhecimento prático e político; e construção de redes de movimento social.

Deepak (2014) reforça que o movimento da Sobal, liderado pela Via Campesina, aborda a equidade de gênero mediante múltiplas estratégias, revelando sua conectividade com o pensamento ecofeminista. Dessa forma, as mulheres da Via Campesina resistem ao patriarcado e ao neoliberalismo por meio de seu envolvimento com o feminismo, criando espaços de liderança na organização, iniciando campanhas e lutando pela Soberania Alimentar.

Conforme destacado por Portman (2018), o compromisso com a defesa dos direitos das mulheres e a igualdade de gênero foi 
incorporado no conceito da Sobal desde suas primeiras articulações. A autora destaca que a política agrícola é uma questão feminina pelo reconhecimento do papel crucial destas na produção de alimentos (enfatizando-se que elas produzem cerca de $70 \%$ da comida consumida na terra). Portman (2018) reflete que há uma necessidade da materialização do poder de decisão igualitário entre homens e mulheres, com políticas de reforma agrária equitativas. A justiça de gênero deveria então orientar o debate sobre a produção de alimentos, sendo abordada mediante linguagem e estrutura da justiça.

A análise fornecida por Portman (2018) indica que a equidade de gênero é parte integrante do conceito de justiça, capaz de fundamentar os objetivos revolucionários da Sobal, a qual implica novas relações sociais livres de opressão e de desigualdade entre mulheres e homens. A Soberania Alimentar se preocupa com a justiça e a sustentabilidade na produção agrícola, considerando a interdependência entre cultura e lugar, comida e comunidade, humanos e natureza.

As reflexões apresentadas por Cabanes Morote e José López (2014) expressam a necessidade de buscar a Soberania Alimentar, e, acima de tudo, a soberania popular, em um processo de cidadania e de empoderamento coletivo que constrói as bases de uma sociedade justa e democrática, em que o poder público e o desenvolvimento dos territórios estejam a serviço do bem-estar da população, a partir da construção de projetos e de iniciativas sustentáveis, de base agroecológica, que revitalizem as economias locais e os laços sociais.

Josefine Glamann et al. (2017) evidenciam que estudos relacionados à agroecologia e à Soberania Alimentar geralmente focam em considerações amplas referentes à sustentabilidade como uma questão de justiça inter e intrageracional, sendo, muitas vezes, argumentado que sistemas de produção baseados na agroecologia se manifestam como mais biodiversos e se constituem como uma estratégia para Sobal.

Os resultados do estudo de Leidy Rodríguez (2016) comprovam a importância da promoção de sistemas agroecológicos, assim como a conversão de sistemas convencionais para sistemas agroecológicos, ao favorecerem experiências bem-sucedidas na 
alimentação, com aumento da variedade de alimentos saudáveis e nutritivos por meio da diversificação de cultivos, uso de energia sustentável e de recursos locais, e manutenção de saberes de agricultoras e agricultores. Tais dinâmicas produtivas contribuem para assegurar a soberania e segurança alimentar e nutricional, não apenas de quem consome, como também de quem produz os alimentos, visto que tende a melhorar as condições de vida de campesinos e campesinas.

Indo além, a investigação de Tabaré Duché-García et al. (2017) evidencia que diversas técnicas com abordagem agroecológica são desenvolvidas em quintais produtivos, reconhecendo-os como espaço com potencial de complementar boa parte da alimentação familiar. Dessa forma, os autores consideram implícita a necessidade do avanço da agroecologia para o desenvolvimento rural, uma vez que tal modelo de agricultura pode gerar impactos positivos na Soberania Alimentar.

Vários estudos, como o de Furtado da Silva, Anjos e Anjos (2016), destacam experiências em quintais produtivos, baseadas em práticas agroecológicas, tendo em comum o protagonismo das mulheres. Consequentemente, como mostram os resultados da pesquisa de Bárbara Flores e Salvador Trevizan (2015), quanto mais forem investidas ações de fomento dos princípios e valores do ecofeminismo, maiores serão as repercussões positivas para o alcance da sustentabilidade ambiental, local e comunitária.

Por fim, reafirmamos que a equidade nas relações de gênero envolve o desenvolvimento humano, a participação de todos e todas, além de estar em consonância com a sustentabilidade social e ambiental.

\section{Conclusões}

Em que pesem os processos desafiadores e as lutas para a ruptura e mudança de paradigmas conceituais, opressões, sistemas agroalimentares protagonizados por mulheres e baseados na agroecologia e no ecofeminismo dão concretude à proposta de um projeto social, político e ambiental capaz de propiciar mudanças e transições necessárias para promover a Soberania e Segurança Alimentar e Nutricional. 
Corroborando as proposições agroecológicas e ecofeministas, infere-se a necessidade de rever as relações entre seres humanos e natureza, priorizando modos de vida mais integrados ao meio ambiente, com promoção de justiça social e equidade gênero. As mudanças sociais a que se fez referência devem estar alinhadas a um sistema de consumo compatível com a natureza, socialmente justo, e a formas de organizar a economia articuladas aos princípios de equidade, igualdade, redistribuição compartilhada de trabalhos de cuidado, solidariedade, reciprocidade e que coloquem a priorização das diversas formas de vida no centro da organização. Para tanto, é imperativo reconhecer que espaços reprodutivos e de cuidado também são espaços de poder.

Diante dessas assertivas, o presente ensaio evidencia as dimensões sociais, culturais, econômicas e políticas do conceito de Soberania Alimentar, conectadas à agroecologia e ao ecofeminismo, e ressalta a produção e o consumo de alimentos agroecológicos protagonizados por mulheres, e como esse contexto inspira e ressignifica outras dinâmicas e modos de ver e atuar no mundo.

\section{REFERÊNCIAS}

ANDERSON, Colin; MAUGHAN, Chris; PIMBERT, Michel. Transformative agroecology learning in Europe: building consciousness, skills and collective capacity for food sovereignty. Agriculture and Human Values, United States, n. 36, p. 531-547, 2018.

BLANCO, Verónica Perales. Ecofeminismo y Ciudad: Mujeres pensando una ciudad más saludable. Revista de Investigación Arte y Ciudad, España, n. 6, p. 7-26, 2014.

BROWNHILL, Leigh; KAARA, Wahu; TURNER, Terisa. Building Food Sovereignty through Ecofeminism in Kenya: From Export to Local Agricultural Value Chains. Canadian Woman Studies les cahiers de la femme, Canada, v. 31, n.1/2, p. 106-112, 2015.

CASSELOT, Marie-Anne. The Inevitability of Care in a Posthuman World. Gnosis: A Journal of Philosophy, Canada, v. 14, n. 2, p. 1-7, 2015.

CONNELL, Raewyn; PEARSE, Rebecca. Gênero: uma perspectiva global. São Paulo: nVersos, 2015. 
DEEPAK, Anne. A Postcolonial Feminist Social Work Perspective on Global Food Insecurity. Affilia: Journal of Women and Social Work, United States, v. 29, n. 2, p. 153-164, 2014.

DUCHÉ-GARCÍA, Tabaré Tonalli et al. Agricultura de traspatio y agreoecología en el proyecto estratégico de seguridad alimentaria (PESAFAO) del estado de Puebla. Agricultura, Sociedad y Desarrollo, México, v. 14, n. 2, p.263-281, 2017.

EVANS, Rebecca. James Tiptree Jr.: Rereading Essentialism and Ecofeminism in the 1970s. Women's Studies Quarterly, New York, v. 43, n. 3/4, p. 223-239, 2015.

FLORES, Bárbara Nascimento; TREVIZAN, Salvador. Ecofeminismo e comunidade sustentável. Revista Estudos Feministas, Florianópolis, SC, v. 23, n. 1, p.11-34, 2015.

FURTADO DA SILVA, Adriella Camila G. F. S.; ANJOS, Mônica de Caldas Rosa, ANJOS, Adilson. Quintais produtivos: para além do acesso à alimentação saudável, um espaço de resgate do ser. Guaju - Revista Brasileira de Desenvolvimento territorial sustentável, Matinhos, PR, v. 2, n. 1, p.77-101, 2016.

GIACOMINI, Terram; TURNER, Terisa; ISLA, Ana; BROWNHILL, Leigh. Ecofeminism against capitalism and for the commons. Capitalism Nature Socialism, United Kingdom, v. 29, n. 1, p. 40-57, 2018.

GIORDANI, Rubia Carla Formighieri; BEZERRA, Islandia; ANJOS, Mônica de Calda Rosa dos. Semeando agroecologia e colhendo nutrição: rumo ao bem e bom comer. In: SAMBUICHI, Regina Helena Rosa et al (Orgs.). A política nacional de agroecologia e produção orgânica no Brasil: uma trajetória de luta pelo desenvolvimento rural sustentável. Brasília: Ipea, 2017.

GLAMANN, Josefine et al. The intersection of food security and biodiversity conservation: a review. Regional Environmental Change, Germany, v. 17, n. 5, p. 1303-1313, 2017.

LACEY, Hugh. Food and Agricultural Systems for the Future: Science, Emancipation and Human Flourishing. Journal of Critical Realism, v. 14, n. 3, p. 272-286, 2015.

LAKE, Osprey Orielle. Women Rising for the Earth: Women are coming together across struggles, borders, and cultures to help build a new world. Earth Island Journal, 2018. Disponível em: https://www.earthisland. org/journal/index.php/magazine/entry/women-rising-for-the-earth/. Acesso em: 10 jan. 2019.

LVC - LA VIA CAMPESINA INTERNACIONAL. Declaración Final del Foro Mundial sobre Soberanía Alimentaria, La Habana, Cuba, 2001. 
MALUF, Renato Sergio et al. Nutrition-sensitive agriculture and the promotion of food and nutrition sovereignty and security in Brazil. Ciência \& Saúde Coletiva, Rio de Janeiro, v. 20, n. 8, p. 2303-2312, 2015.

MCKINNEY, Laura. Gender, democracy, development, and overshoot: a cross-national analysis. Population and Environment, v. 36, n. 2, p. 193-218, 2014.

MEINZEN-DICK, Ruth; KOVARIK, Chiara; QUISUMBING, Agnes. Gender and Sustainability. Annual Review of Environment and Resources, v. 39, p. 29-56, 2014.

MELERO-AGUILAR, Noelia; LIMÓN-DOMÍNGUEZ, Dolores. Educar en espacios comunitarios de participación, cooperación y ecodesarrollo desde una perspectiva ecofeminista. Revista Electrónica Educare, USA, v. 1, p. 1-11, 2017.

MOROTE, Cabanes; LÓPEZ, José Daniel Gómez. Economía social y Soberanía Alimentaria. Aportaciones de las cooperativas y asociaciones agroecológicas de producción y consumo al bienestar de los territorios. Revista de Economía Pública, Social y Cooperativa, España, v. 82, p. 127-154, 2014.

MOURA, Iracema Ferrerira de; GUEDES, Cezar Augusto Miranda; ASSIS, Renato Linhares de. La agroecología en la agenda del Gobierno brasileño: desarrollos entre 2011 y 2014. Cuadernos de Desarrollo Rural, Bogotá, v. 14, n. 79 , p. 1-15, 2017.

MUDREK, Camila. “Porque a gente cuida": o ecofeminismo e a agroecologia na promoção da soberania alimentar - junções e significados para mulheres da agricultura camponesa na região central do Paraná. 2015. Trabalho de Conclusão de curso (Curso de Ciências Sociais) - Setor de Ciências Humanas, Letras e Artes, Universidade Federal do Paraná, Curitiba, 2015.

PORTMAN, Anne. Food Sovereignty and Gender Justice. Journal of Agricultural and Environmental Ethics, Netherlands, v. 31, n. 4, p. 455466, 2018.

PULEO, Alicia Helda. Liberdad, igualdad, sostenibilidad. Por um ecofeminismo ilustrado. Isegoría, España, v. 39, p. 39-59, 2008.

RAMíREZ, Gezbel Guzmán; MÁRQUEZ, Martha Bolio. Construyendo la herramienta perspectiva de gênero: cómo portar lentes nuevos. México: Universidad Iberoamericana, 2010.

RODRÍGUEZ, Leidy Casimiro. Need of an agroecological transition in Cuba, perspectives and challenges. Pastos y Forrajes, Cuba, v. 39, n. 3, p. 8191, 2016. 
ROSENDO, Daniela. Sensível ao cuidado: uma perspectiva ética ecofeminista. Curitiba: Prisma, 2015.

SAGE, Colin. Food security, food sovereignty and the special rapporteur: Shaping food policy discourse through realising the right to food. Dialogues in Human Geography, US, v. 4, n. 2, p. 168-181, 2014.

SAGOLS, Lizbeth. El ecofeminismo y su expresión en la filosofia de Karen Warren. Una perspectiva ética. Debate Feminista, México, v. 49, n. 25, p. 116-124, 2014.

SESMA, Angélica Velasco. Ética del cuidado para la superación del androcentrismo: hacia una ética y una política ecofeministas. Revista Ibero-Americana de Ciência, Tecnologia e Sociedade, España, v. 11, n. 31, p. 171-193, 2016.

SILIPRANDI, Emma. Ecofeminismos: mulher, natureza e outros tipos de opressão. In: ENCONTRO FAZENDO GÊNERO, 7, SIMPÓSIO TEMÁTICO, 31, 2008, Florianópolis: Universidade Federal de Santa Catarina, 2008.

SILIPRANDI, Emma. Mulheres e agroecologia: transformando o campo, as florestas e as pessoas. Rio de Janeiro: Editora UFRJ, 2015.

SILVA, Severino Arruda da. Ecofeminismo: em defesa da dignidade das mulheres e da natureza. In: SIMPÓSIO INTERNACIONAL DE MARIOLOGIA - UNICAP, 13., 2017, Recife. Anais [...]. Recife: UNICAP, 2017. p. 279-286.

SWANSON, Lori. A Feminist Ethic that Binds Us to Mother Earth. Ethics and the Environment, v. 20, n. 2, p. 83-103, 2015.

TEJEDA, Abril Saldaña. Ecofeminismo, mujeres y desarrollo sustentable: el caso de la Sierra de Santa Rosa en Guanajuato. Región y Sociedad, v. 27, n. 62, p.63-96, 2015.

TRIANA, Diana Paola. Éticas ecofeministas: a comunidade da vida. Cuadernos de Filosofía Latinoamericana, Bogotá, v. 37, n. 114, p. 117131, 2016.

VIVAR-ARENAS, Josefina. Claiming the nature. An approach to the ecofeminists perspectives. Revista Ra Ximhai, México, v. 11, n. 2, p. 8191, 2015.

WARREN, Karen. Filosofías ecofeministas. España: Icara, 2003.

WEZEL, Alexander et al. Agroecology in Europe: research, education, collective action networks, and alternative food systems. Sustainability, v. 10, n. 1214, p. 1-18, 2018.

WOLLSTONECRAFT, Mary. Reivindicação dos direitos das mulheres. São Paulo: EPIDRO, 2015. 